\title{
Reinforcement Size Dependence of Load Bearing Capacity in Ultrafine-Grained Metal Matrix Composites
}

\author{
HANRY YANG, LIN JIANG, MARTIN BALOG, PETER KRIZIK, \\ and JULIE M. SCHOENUNG
}

The length-scale effects on the load bearing capacity of reinforcement particles in an ultrafine-grained metal matrix composite (MMC) were studied, paying particular attention to the nanoscale effects. We observed that the nanoparticles provide the MMCs with a higher strength but a lower stiffness compared to equivalent materials reinforced with submicron particles. The reduction in stiffness is attributed to ineffective load transfer of the local stresses to the small and equiaxed nanoparticles.

DOI: $10.1007 / \mathrm{s} 11661-017-4186-7$

(C) The Minerals, Metals \& Materials Society and ASM International 2017

\section{INTRODUCTION}

PARTICUlate-REINFORCED metal matrix composites (MMCs) are well known to have enhanced mechanical properties - such as stiffness, strength, hardness, and fracture toughness - compared to monolithic metal alloys. ${ }^{[1-11]}$ In a drive to further enhance the properties of MMCs, recent research has focused on reducing the reinforcement particle size from the micrometric regime to submicron and nanometric length scales. ${ }^{[6,9]}$ The strength and hardness of nanoparticle-reinforced composites have been extensively studied and the operative strengthening mechanisms have been thoroughly described ${ }^{[6,9,12,13]}$ with the general finding that as the reinforcement particle size decreases, the strength of the composite increases. The reduction in the reinforcement particle size also reduces stress concentrations at the reinforcement particle corners and leads to a consequential increase in work hardenability due to reinforcement-dislocation interactions, which results in enhanced ductility. ${ }^{[6,7,9]}$

HANRY YANG is with the Department of Chemical Engineering \& Materials Science, University of California Davis, Davis, CA 95616, and also with the School of Mechanical \& Materials Engineering, Washington State University, Pullman, WA, 99163. LIN JIANG and JULIE M. SCHOENUNG are with the Department of Chemical Engineering \& Materials Science, University of California Davis, and also with the Department of Chemical Engineering \& Materials Science, University of California Irvine, Irvine, CA 92697. Contact e-mail:julie.schoenung@uci.edu MARTIN BALOG and PETER KRIZIK are with the Institute of Materials and Machine Mechanics, Slovak Academy of Sciences, Racianska 75, 83102 Bratislava, Slovakia.

Manuscript submitted January 28, 2017.

Article published online July 5, 2017
However, nanoscale effects on the stiffness of MMCs have not been well documented. For example, $\mathrm{B}_{4} \mathrm{C}$ is an excellent candidate as a stiffening component in MMCs due to its high elastic modulus of $460 \mathrm{GPa}^{[14]}$ compared to $70 \mathrm{GPa}$ for Al. Even relatively small additions of micron-sized $\mathrm{B}_{4} \mathrm{C}$ will result in substantial predicted increases in the composite's stiffness. However, as the development of MMCs pushes the reinforcement size to the nanometric regime, it is unclear whether the nanometric $\mathrm{B}_{4} \mathrm{C}$ particles will continue to be effective stiffeners. Therefore, a systematic study into the dependence of elastic modulus on reinforcement particle size is required to solve this puzzle. Generally, because elastic modulus is an intrinsic property of a pure substance, dictated by its atomic bonding characteristics, it is often also considered to be a structure independent material property in more complex materials, and therefore, particle size is generally not considered when predicting the elastic modulus of a composite. Typically, only the volume fraction of the reinforcement phase is considered, such as in the traditional rule-of-mixtures (ROM) approximation. With this traditional approach, for a constant volume fraction of reinforcement particles, the elastic modulus should not change as the reinforcement particle size is decreased. The experimental observations in the current study, however, show otherwise.

It is the goal of this publication to shed light on the factors that influence the effectiveness of nanoparticles as load bearing components in MMCs. Al- $\mathrm{B}_{4} \mathrm{C}$ composites were chosen as a model MMC for this study, because $\mathrm{Al}-\mathrm{B}_{4} \mathrm{C}$ 's strong, hard, and tough qualities make it a desirable material for use as armor on vessels like submarines and aircraft carriers. ${ }^{[15]}$ Two types of $\mathrm{B}_{4} \mathrm{C}$ particles, $\mathrm{n}-\mathrm{B}_{4} \mathrm{C}(50 \mathrm{~nm})$ and $\mathrm{s} \mu-\mathrm{B}_{4} \mathrm{C}(500 \mathrm{~nm})$, were, respectively, incorporated into the $\mathrm{Al}$ matrix via 
cryomilling (ball milling of $\mathrm{B}_{4} \mathrm{C}$ and $\mathrm{Al}$ powders in liquid $\mathrm{N}_{2}$ ) under identical processing conditions and with the same nominal $\mathrm{B}_{4} \mathrm{C}$ volume fraction of 5 vol pct. The mechanical properties of these two $\mathrm{Al}-\mathrm{B}_{4} \mathrm{C}$ composites were compared, paying particular attention to the strength and elastic modulus. The elastic modulus was shown to decrease with decreasing reinforcement particle size while the strength increased. Both the ROM and a variational approach proposed by Hashin and Shtrikman ${ }^{[16]}$ are considered to predict the elastic modulus, but neither model can predict any differences in elastic modulus due to changes in the reinforcement particle size. The decreased elastic modulus of nanoparticle-reinforced MMCs was attributed to ineffective load transfer of nanoparticles located at grain boundaries, whereas only nanoparticles located in the grain interiors contributed to the composites overall stiffness.

\section{EXPERIMENTAL APPROACH}

Gas atomized -325 mesh aluminum alloy 5083 (AA 5083; Al-4.5Mg-0.57Mn-0.25Cr; Valiment Inc, Stockton, CA) powder and $\mathrm{B}_{4} \mathrm{C}$ powder were cryomilled for 12 hours in liquid nitrogen using a modified Svegvari $1 \mathrm{~S}$ Union Process attritor. A rotational velocity of 180 RPM and a ball-to-powder ratio of 30:1 were used. $0.2 \mathrm{wt}$ pet stearic acid $\left(\mathrm{CH}_{3}\left(\mathrm{CH}_{2}\right)_{16} \mathrm{CO}_{2} \mathrm{H}\right)$ was added as a process control agent to prevent excessive cold welding during cryomilling. A more complete description of the cryomilling process was outlined by Witkin and Lavernia. ${ }^{[17]} \mathrm{B}_{4} \mathrm{C}$ particles of two distinct mean diameters, 50 nm (fabricated and provided by US Army Armament, Research, Development and Engineering CenterPicatinny, NJ), hereafter referred to as $n-B_{4} C$, and $500 \mathrm{~nm}$ (H.C. Starck-Newton, MA), hereafter referred to as $\mathrm{s} \mu-\mathrm{B}_{4} \mathrm{C}$, were used. Two different batches of cryomilled powder, one with 5 vol pct of $n-B_{4} C$ and the other with 5 vol pct $s \mu-B_{4} C$, were fabricated for this study. The cryomilled powders were stored in a nitrogen gas glovebox with a nominal trace oxygen content of $<50$ ppm to prevent oxidation of the cryomilled powders prior to consolidation.

Each batch of cryomilled powder was encapsulated in an AA 6061-O can and hot vacuum degassed for 20 hours at a maximum temperature of $773 \mathrm{~K}\left(500^{\circ} \mathrm{C}\right)$ with a final pressure of $<1 \times 10^{-6}$ torr. The degassed powders were then consolidated by dual-mode dynamic forging (DMDF) in two steps. ${ }^{[18]} \mathrm{DMDF}$ was carried out using dies heated to $673 \mathrm{~K}\left(400{ }^{\circ} \mathrm{C}\right)$ and an applied axial pressure of $\sim 250 \mathrm{MPa}$. The first step was carried out in a closed die, while the second step was carried out in an open die.

Three different materials were successfully fabricated under the above-described identical processing conditions with the exception of $\mathrm{B}_{4} \mathrm{C}$ reinforcement type. Sample 1 was reinforced with 5 vol pet n-B ${ }_{4}$, Sample 2 was reinforced with 5 vol pct $\mathrm{s} \mu-\mathrm{B}_{4} \mathrm{C}$, and Sample 3 contained no reinforcement particles. The concentration of light elements- $\mathrm{H}, \mathrm{O}, \mathrm{C}$, and $\mathrm{N}$-was measured by LECO Corporation (St. Joseph, MI). C was measured using a CS600 combustion infrared detection analyzer.
$\mathrm{H}$, $\mathrm{O}$, and $\mathrm{N}$ were measured using a TCH600 inert gas fusion analyzer. Metallographic samples used for microstructural evaluation in a FEI Scios scanning electron microscope (SEM) equipped with an energy dispersive spectroscopy (EDS) detector were polished with a JEOL SM-09010 cross section ion polisher. Transmission electron microscopy (TEM) samples were mechanically thinned to $<20 \mu \mathrm{m}$ thickness and then ion milled to electron transparency using a Gatan PIPS 691 ion-milling machine cooled by liquid nitrogen. TEM micrographs were acquired on a Phillips CM-12 TEM operated at $120 \mathrm{kV}$ or a JOEL JEM-2500SE operated at $200 \mathrm{kV}$.

The elastic modulus of each material was determined using a 3-point bend test on a dynamic mechanical analysis (DMA) Q80 TA Instruments machine. The DMA bend test specimens were machined longitudinally to the transverse direction with dimensions of $2.5 \times 4 \times 55 \mathrm{~mm}$. The dimensions of the DMA specimens were measured with an accuracy of $0.005 \mathrm{~mm}$. Room temperature testing was conducted with a frequency of $1 \mathrm{~Hz}$, a preload force of $0.5 \mathrm{~N}$, and a sinusoidal force with an amplitude of $3.5 \mathrm{~N}$ (an approximate bending stress of $22.5 \mathrm{MPa}$ ) for 3 minutes. Two samples of each material were each tested two times on each side.

The mechanical response during compression testing was measured using an Instron 8801 universal testing machine equipped with a $100 \mathrm{kN}$ load cell. All compression samples were $5 \times 3 \times 3 \mathrm{~mm}$ and conformed to ASTM E9 standard. A nominal strain rate of $10^{-3} \mathrm{~s}^{-1}$ was used. The strain was measured using a video extensometer.

\section{RESULTS}

The density of the consolidated samples was found to be $0.99,0.96$, and 1.03 of theoretical density $(2.65 \mathrm{~g} /$ $\mathrm{cm}^{3}$ ), for Samples 1, 2, and 3, respectively, using the Archimedes method. The higher than theoretical density of Sample 3 is due to the uptake of oxygen and nitrogen during cryomilling (see Table I). Representative SEM micrographs for Samples 1 and 2, provided in Figure 1, show that the $\mathrm{B}_{4} \mathrm{C}$ particles are well dispersed and no significant amount of porosity was observed.

The average $\mathrm{Al}$ grain size was measured from more than 200 individual grains observed by TEM to be $154 \pm 74$ and $240 \pm 84 \mathrm{~nm}$ for Samples 1 and 2, respectively. Representative bright-field and corresponding dark-field micrographs are shown in Figure 2. The grain size distribution histograms are shown in Figure 3. Scanning transmission electron microscopy (STEM) micrographs highlighting the location of the $\mathrm{B}_{4} \mathrm{C}$ particles relative to the $\mathrm{Al}$ grains are shown in Figure 4 . The characteristics of the interfaces between the $\mathrm{B}_{4} \mathrm{C}$ particles and their neighboring $\mathrm{Al}$ grains in materials fabricated using the same process conditions have been previously reported in Reference 7 and are not discussed in detail here.

The mechanical behavior exhibited by the three samples is summarized in Table II. Additional 
Table I. Summary of Light Element Content

\begin{tabular}{lccccc}
\hline ID & Reinforcement & Carbon $($ Pct) & Nitrogen (Pct) & Oxygen (Pct) & Hydrogen (ppm) \\
\hline Sample 1 & $\mathrm{n}-\mathrm{B}_{4} \mathrm{C}$ & 1.15 & 0.96 & 0.40 & 52 \\
Sample 2 & s $\mu$-B ${ }_{4} \mathrm{C}$ & 1.22 & 0.97 & 0.63 & 13 \\
Sample 3 & N/A & 0.18 & 0.55 & 0.41 & 27 \\
\hline
\end{tabular}
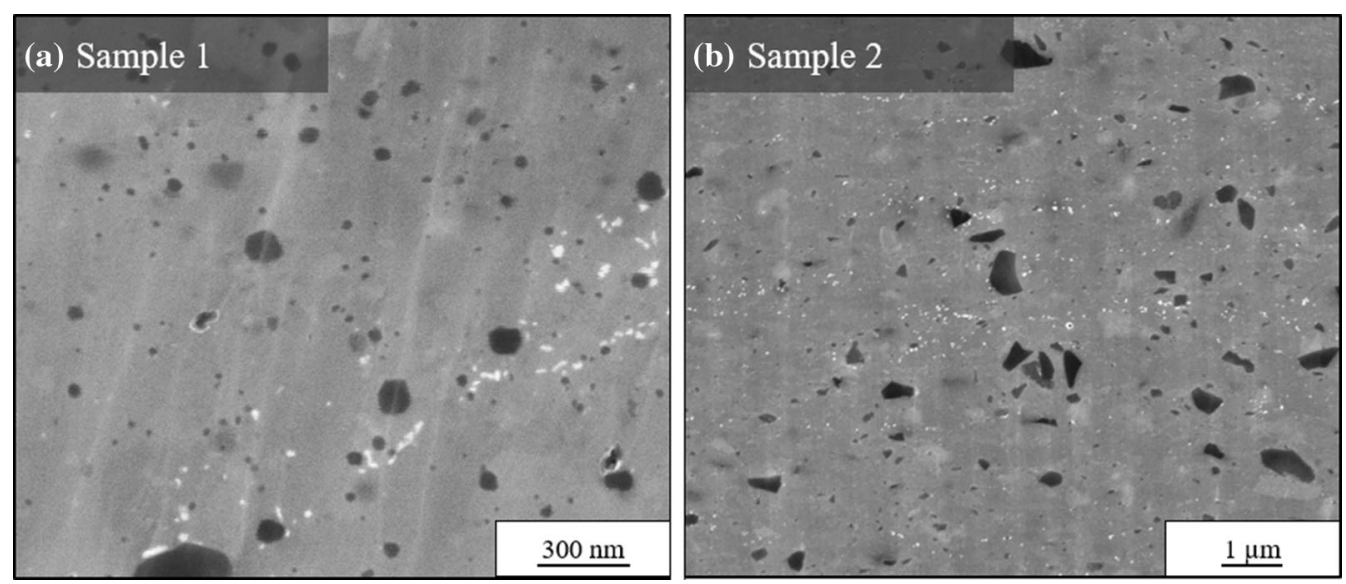

Fig. 1-Representative SEM micrographs for (a) Sample 1 and (b) Sample 2, showing the dispersion of $\mathrm{B}_{4} \mathrm{C}$ particles (black particles) within the metal matrix. The white particles are remnants of the disrupted native oxide film from the aluminum particles. Note the differences in scale.
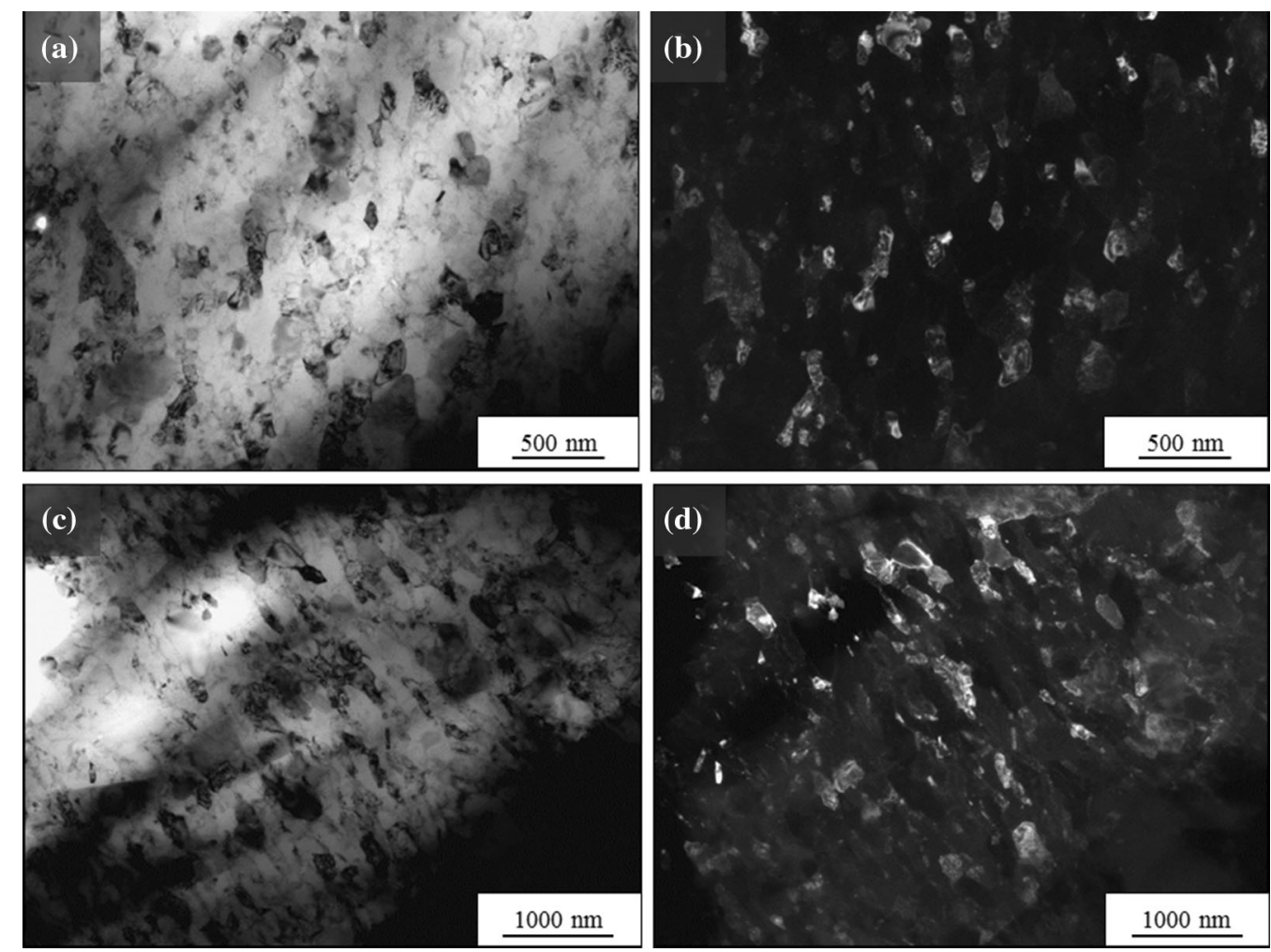

Fig. 2-Representative TEM micrographs for Sample 1 in $(a)$ bright-field and $(b)$ dark-field, and Sample 2 in $(c)$ bright-field and $(d)$ dark-field. Note the differences in scale.

previously reported data on cryomilled 100 pct UFG AA $5083^{[13]}$ are also reported in Table II, as a point of comparison. The elastic modulus values for Samples 1, 2 , and 3 were $78.1 \pm 0.3,82.7 \pm 0.2$, and $71.5 \pm$
$0.3 \mathrm{GPa}$, respectively. Less than 0.3 pct variation in elastic modulus was measured within each sample. The compressive yield strength values for Samples 1 and 2 were 830 and $750 \mathrm{MPa}$, respectively. Both samples were 


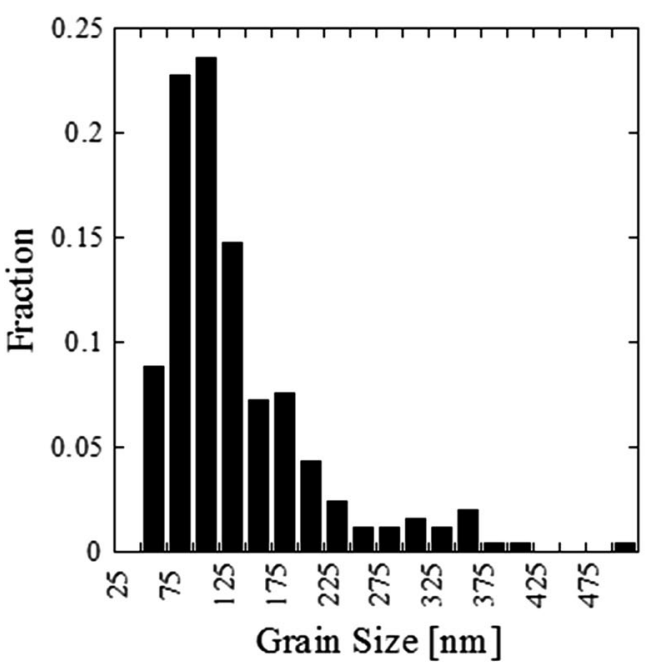

(a)

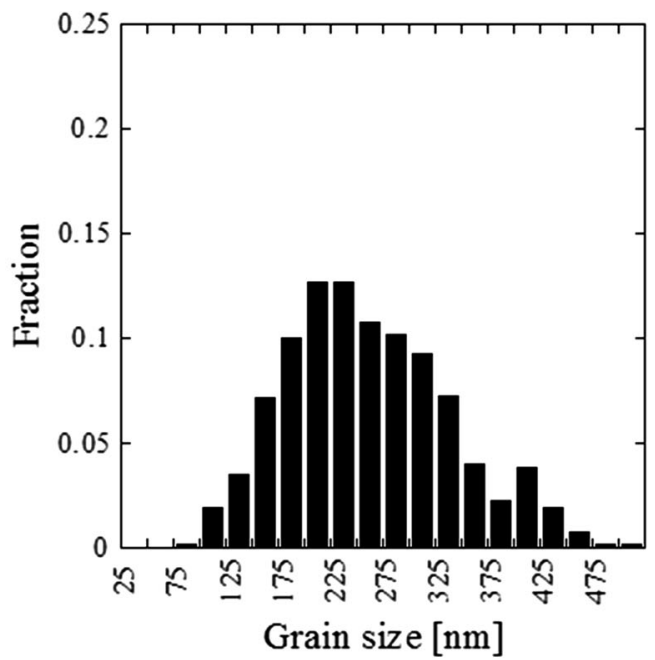

(b)

Fig. 3-Grain size distributions for (a) Sample 1 and (b) Sample 2.
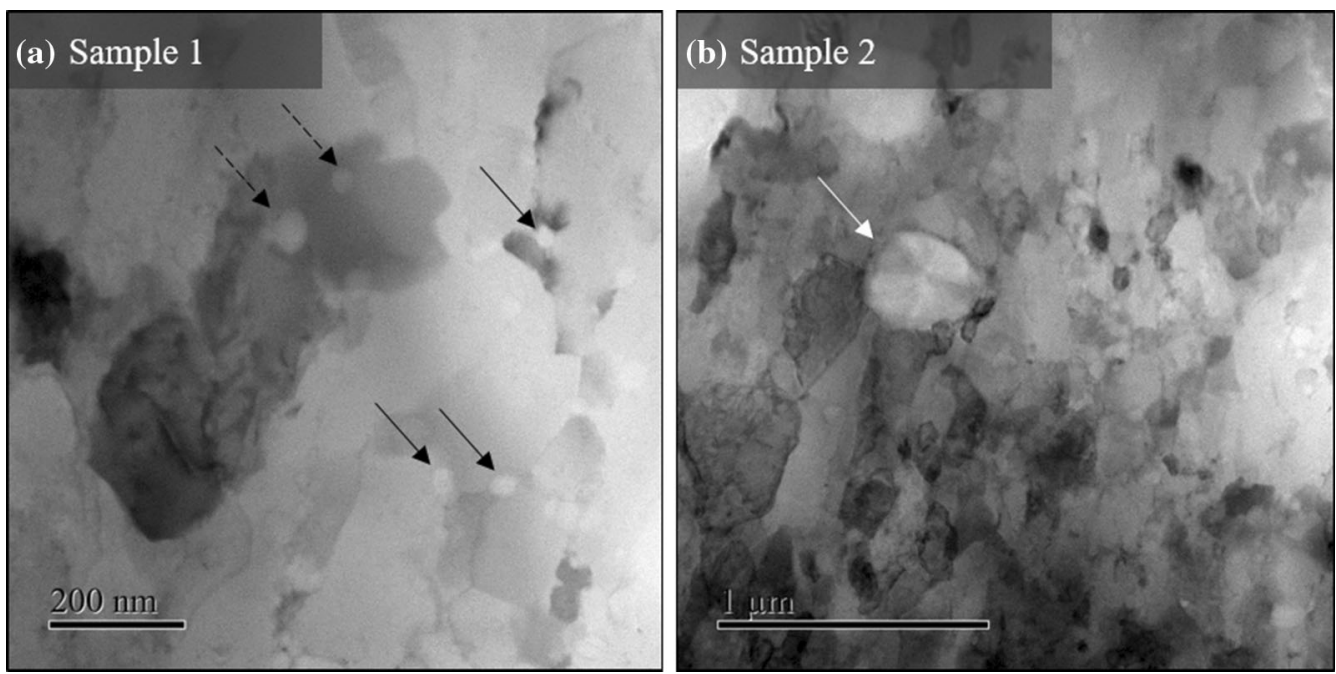

Fig. 4 - Scanning transmission electron microscopy micrographs of (a) Sample 1 and (b) Sample 2, showing the Al grain structure around the appropriate reinforcement particles. $n-\mathrm{B}_{4} \mathrm{C}$ particles are highlighted by black arrows, and a $\mathrm{s} \mu-\mathrm{B}_{4} \mathrm{C}$ particle is indicated by a white arrow. $\mathrm{B}_{4} \mathrm{C}$ particles located at grain boundaries are indicated using solid arrows, while intragranular $n-\mathrm{B}_{4} \mathrm{C}$ particles are indicated by dashed arrows. Note the differences in scale.

significantly stronger than conventional AA 5083-O, which yields at $\sim 134 \mathrm{MPa} \cdot{ }^{[19]}$ Despite the difference in yield strength, both samples had similar compressive strain-to-failure values of $\sim 0.17$. The toughness values were calculated to be 135 and $120 \mathrm{MJ}$ for Samples 1 and 2 , respectively. In both samples, slight strain softening was observed.

\section{DISCUSSION}

Samples 1 and 2 have identical nominal composition and thermomechanical processing routes, but the elastic modulus of Sample 2 is $\sim 5 \mathrm{GPa}$ (6 pct) higher than that of Sample 1. Sample 3 has a measured modulus of $71.5 \mathrm{GPa}$, which agrees with the expected value of
$72 \mathrm{GPa}$ for conventional AA5083. ${ }^{[19]}$ The agreement in modulus for cryomilled and conventional AA5083 shows that there is no significant dependence of elastic modulus on grain size or due to the incorporation of dispersoids from cryomilling, which is consistent with previous studies. ${ }^{[20,21]}$ The increase in modulus in the composite materials (Samples 1 and 2) relative to the unreinforced material (Sample 3) is expected. However, further consideration is required to explain the difference between Samples 1 and 2. To do so, we consider various methods for estimating elastic modulus and complement this with an analysis of strengthening mechanisms.

As a first approximation, the upper bound for elastic modulus in a metal matrix composite, $E_{\mathrm{c}}$, can be estimated using the simple ROM expressed as ${ }^{[22]}$ 
Table II. Summary of Mechanical Properties

\begin{tabular}{lcccc}
\hline Sample ID & Elastic Modulus $(\mathrm{GPa})$ & Yield Strength $(\mathrm{MPa})$ & Strain-to-failure $(\mathrm{mm} / \mathrm{mm})$ & Toughness $(\mathrm{MJ})$ \\
\hline Sample 1 & 78.1 & 830 & 0.165 & 0.17 \\
Sample 2 & 82.7 & 750 & - & 135 \\
Sample 3 & 71.5 & - & 0.30 & - \\
100 pct UFG & {$[13]$} & - & 558 & - \\
\hline
\end{tabular}

$$
E_{\mathrm{c}}=f_{\mathrm{m}} E_{\mathrm{m}}+\sum_{i} E_{i} f_{i},
$$

where $f_{\mathrm{m}}, E_{\mathrm{m}}, f_{i}$, and $E_{i}$ are the volume fraction and elastic modulus of the matrix and reinforcement species, respectively. Assuming a simple two-component system consisting of ultrafine-grained (UFG) AA5083-which has an elastic modulus equivalent to that measured in Sample $3 \quad(E=71.5 \mathrm{GPa})$ - and $5 \mathrm{vol}$ pct $\mathrm{B}_{4} \mathrm{C}$ $(E=460 \mathrm{GPa})$, Eq. [1] predicts an upper bound for the elastic modulus of $90.9 \mathrm{GPa}$.

For two-component systems, the lower bound of elastic modulus is approximated as ${ }^{[22]}$

$$
E_{\mathrm{c}}=\frac{E_{\mathrm{m}} E_{\mathrm{r}}}{f_{\mathrm{r}} E_{\mathrm{m}}+f_{\mathrm{m}} E_{\mathrm{r}}},
$$

where the subscripts $m$ and $r$ indicate the metal matrix and reinforcement phase, respectively, resulting in an estimated lower bound for elastic modulus of $75 \mathrm{GPa}$. The experimentally measured values fall within the estimated upper and lower bounds, which indicates that the $\mathrm{B}_{4} \mathrm{C}$ particles of both sizes contribute to the composites' elastic moduli. Nonetheless, the measured values for elastic modulus fall toward the low end of the estimated bounds.

A second model proposed by Hashin and Shtrikman can also be used to predict the elastic modulus. ${ }^{[16]}$ In the H-S model, variational principles are used to bound the strain energy stored in a given cube of material under a uniform stress. Specifically, the reinforcement phase is assumed to be spherical in morphology, which is a reasonable assumption for the Al- $\mathrm{B}_{4} \mathrm{C}$ systems used in this study. The upper and lower bounds for the bulk modulus, $K_{\mathrm{U}} / K_{\mathrm{L}}$, and shear modulus, $G_{\mathrm{U}} / G_{\mathrm{L}}$, respectively, are

$$
\begin{gathered}
K_{\mathrm{U}}^{*}=K_{\mathrm{R}}+\frac{1-f_{\mathrm{R}}}{\frac{1}{K_{\mathrm{M}}-K_{\mathrm{R}}}+\frac{3 f_{\mathrm{R}}}{3 K_{\mathrm{R}}+4 G_{\mathrm{R}}}} \\
K_{\mathrm{L}}^{*}=K_{\mathrm{M}}+\frac{f_{\mathrm{R}}}{\frac{1}{K_{\mathrm{R}}-K_{\mathrm{M}}}+\frac{3\left(1-f_{\mathrm{R}}\right)}{3 K_{\mathrm{M}}+4 G_{\mathrm{M}}}} \\
G_{\mathrm{U}}^{*}=G_{\mathrm{R}}+\frac{1-f_{\mathrm{R}}}{\frac{1}{G_{\mathrm{M}}-G_{\mathrm{R}}}+\frac{6\left(K_{\mathrm{R}}+2 G_{\mathrm{R}}\right) f_{\mathrm{R}}}{5 G_{\mathrm{R}}\left(3 K_{\mathrm{R}}+4 G_{\mathrm{R}}\right)}} \\
G_{\mathrm{L}}^{*}=G_{\mathrm{M}}+\frac{\frac{1}{f_{\mathrm{R}}}}{\frac{6\left(K_{\mathrm{M}}+2 G_{\mathrm{M}}\right)\left(1-f_{\mathrm{R}}\right)}{5 G_{\mathrm{M}}\left(3 K_{\mathrm{M}}+4 G_{\mathrm{M}}\right)}},
\end{gathered}
$$

where $K, G$, and $f$ are the bulk modulus, shear modulus, and volume fraction, respectively, of the metal matrix and reinforcement phases as denoted by the subscripts " $M$ " and " $R$." The effective elastic modulus is simply approximated by the common relationship:

$$
\begin{gathered}
E_{i}=\frac{9 K_{i} G_{i}}{\left(3 K_{i}+G_{i}\right)} \\
E_{\mathrm{U}}=79.9 \mathrm{GPa} \\
E_{\mathrm{L}}=73.1 \mathrm{GPa} .
\end{gathered}
$$

The H-S model predicts tighter bounds than the ROM and shows excellent agreement for Sample 1 (measured $E=78.1 \mathrm{GPa}$ ), but underestimates the elastic modulus of Sample 2 (measured $E=82.9 \mathrm{GPa}$ ).

Neither of the two models considers any influence of reinforcement size nor shape on the elastic modulus; however, the experimental results clearly indicate that these parameters do indeed affect the elastic modulus. If one only considers the bounds set by the ROM, then both $n-B_{4} C$ and $s \mu-B_{4} C$ particles appear to be poor stiffeners relative the theoretical expectation. According to the H-S model, both reinforcement sizes are effective stiffeners. The ROM assumes that there is perfect transfer of stress across interfaces between the matrix and reinforcement phases; however, a perfect transfer is not realistic. For continuous and short fibers, there are relatively few interfaces and the structural (i.e., interface related) influences are generally ignored. However, as the reinforcement particle size becomes very small, the fraction of interfaces increases exponentially and it becomes less efficient for the stress to be transferred through the reinforcement phase, and is instead sustained by the metal matrix. Hence, nanoparticles are less efficient load bearing components than larger particles or fibers. This is not surprising as continuous fiber-reinforced composites generally show higher stiffness than short fiber-reinforced composites with similar volume fractions of reinforcement. ${ }^{[21]}$

It is worth stating that the elastic modulus can be simply defined by the amount of strain energy stored per unit volume within the material under an applied stress (or strain), which can be expressed as $U \propto \sigma \varepsilon=E \varepsilon^{2}$, by Hook's Law. In an ideal two-component system, the interface has perfect bonding in the sense that any elastic strain along the interface is identical both within the reinforcement phase and the metal matrix: or $\varepsilon_{R}=\varepsilon_{\mathrm{M}}$. If this boundary condition is met, the stiffer reinforcement phase will sustain a higher local stress than the less stiff matrix, i.e., the reinforcement will be load bearing. But in real systems, the interfaces between the reinforcement and the matrix are not perfect and, furthermore, are influenced by microstructure and the placement of the relative phases. The micrograph in Figure 4(a) illustrates that for Sample 1, the $n-B_{4} C$ 


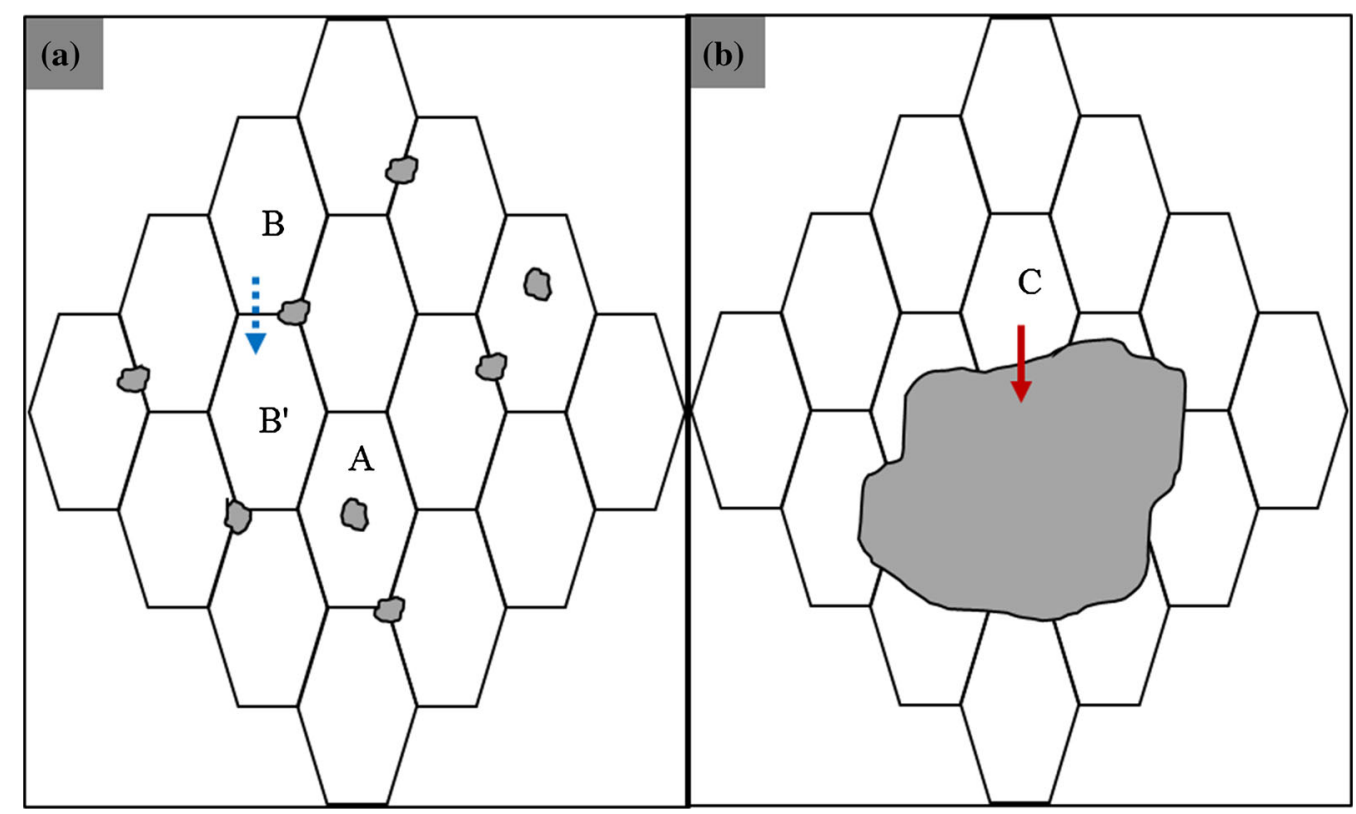

Fig. 5- Schematic representation of load transfer for: $(a) \mathrm{n}-\mathrm{B}_{4} \mathrm{C}$-reinforced $\mathrm{Al}$, and $(b) \mathrm{s} \mu-\mathrm{B}_{4} \mathrm{C}$-reinforced $\mathrm{Al}$. The dashed blue arrow represents load transfer between adjacent $\mathrm{Al}$ grains despite the presence of a nearby $\mathrm{n}-\mathrm{B}_{4} \mathrm{C}$ particle. The solid red arrow represents load transfer from an $\mathrm{Al}$ grain directly to the $\mathrm{s} \mu-\mathrm{B}_{4} \mathrm{C}$ particle.

particles can be located either at grain boundaries or at grain interiors since the particles are smaller in size than the grains. In contrast, in Sample 2 (see Figure 4(b)), the $\mathrm{s} \mu-\mathrm{B}_{4} \mathrm{C}$ particles are larger than the matrix grains, so they must be located at grain boundaries. In addition, the interfaces between the matrix and the intragranular $\mathrm{n}-\mathrm{B}_{4} \mathrm{C}$ particles (i.e., located in the grain interiors) have been shown to be semi-coherent, whereas for intergranular $\mathrm{n}-\mathrm{B}_{4} \mathrm{C}$ particles (i.e., located at grain boundaries) incoherent interfaces were observed. ${ }^{[\pi]}$ For the former, the $\mathrm{Al}$ lattice is constrained and the boundary condition holds $\varepsilon_{\mathrm{R}}=\varepsilon_{\mathrm{M}}$, whereas for the latter, the misfit strain can be accommodated by the matrix and $\varepsilon_{\mathrm{R}} \neq \varepsilon_{\mathrm{M}}$.

In an effort to summarize the role of these different microstructures and interfaces on potential load transfer, a schematic for a representative applied vertical load is provided in Figure 5. Please note that this schematic represents a simplified example of stress being transferred through a few specified points, and the actual stress state will be complex throughout the material. In this schematic, the small $\mathrm{n}-\mathrm{B}_{4} \mathrm{C}$ particles are located at grain boundaries, triple points, and inside the grain interiors, as in Sample 1. When the $n-B_{4} C$ particles are located in the grain interior (such as in Grain A in Figure 5(a)), then the $\mathrm{n}-\mathrm{B}_{4} \mathrm{C}$ will stiffen the material due to the boundary condition $\varepsilon_{\mathrm{R}}=\varepsilon_{\mathrm{M}}$. However, when the $\mathrm{n}-\mathrm{B}_{4} \mathrm{C}$ particles are located at grain boundaries, the stress being transferred from Grain B will simply transfer to Grain B' and not through the $n-\mathrm{B}_{4} \mathrm{C}$ particle located at the boundary, as indicated by the dashed arrow. However, for $s \mu-B_{4} C$ particles (Figure 5(b)), when stress is being transferred from Grain $\mathrm{C}$, it must be transferred to the $s \mu-\mathrm{B}_{4} \mathrm{C}$ particle because there is no adjacent $\mathrm{Al}$ grain in the loading direction, as indicated by the solid arrow. In an effort to expand on this schematic to quantify the role load transfer has on the elastic modulus, we assume that 40 pct of the $n-B_{4} C$ particles in Sample 1 are located in the grain interiors, ${ }^{[7]}$ and that only these contribute to the composite's stiffness. In this case, Eq. [1] predicts an elastic modulus of $79.4 \mathrm{GPa}$, which is much closer to the experimental modulus of $78.1 \mathrm{GPa}$.

If the above argument for elastic modulus is true, then diminished strengthening due to reduced load bearing is also anticipated. However, load bearing is not the only mechanism by which reinforcement particles may strengthen a material. When the reinforcement particles are sufficiently small, they can strengthen the material by hindering dislocation motion via Orowan bowing. Nanoparticles will also indirectly strengthen a material by pinning grain boundaries during thermomechanical processing resulting in a finer final grain size and therefore higher strength via the Hall-Petch relationship. Lastly, the presence of reinforcement particles will increase the material's dislocation density through the introduction of geometrically necessary dislocations. In order to deconvolute the strengthening mechanisms that are operative in Samples 1 and 2, various strengthening mechanisms are described in detail below:

The reinforcement particle's contribution to strengthening via load transfer is estimated by the rule-of-mixtures as ${ }^{[3]}$

$$
\Delta \sigma_{\mathrm{LT}}=f_{\mathrm{R}} \sigma_{\mathrm{R}}
$$

where $f_{\mathrm{R}}$ is the volume fraction of reinforcement particles and $\sigma_{\mathrm{R}}$ is the strength of $\mathrm{B}_{4} \mathrm{C}(2900 \mathrm{MPa}) \cdot{ }^{[4]}$ For 5 vol pct $\mathrm{B}_{4} \mathrm{C}$ particles, assuming all particles contribute to load bearing, this leads to an estimated $\Delta \sigma_{\mathrm{LT}}=145 \mathrm{MPa}$ for both samples.

As expected, the average metal grain size in Sample 1 is finer than in Sample 2 with grain sizes of 154 and 240 
$\mathrm{nm}$, respectively. The contribution to strength due to the refined grain size is ${ }^{[23,24]}$

$$
\Delta \sigma_{\mathrm{H}-\mathrm{P}}=k_{\mathrm{HP}} / \sqrt{D},
$$

where $k_{\mathrm{HP}}=0.165$ is the Hall-Petch constant for cryomilled $\mathrm{Al}-5 \mathrm{Mg}$ alloys ${ }^{[18]}$ and $D$ is the mean grain size of the metal matrix. Accordingly, $\Delta \sigma_{\mathrm{H}-\mathrm{P}}=420$ and $337 \mathrm{MPa}$ for Samples 1 and 2, respectively.

The metal matrix used in this study is AA 5083 which contains $4.5 \mathrm{wt}$ pet $\mathrm{Mg}$. The $\mathrm{Mg}$ in this alloy is a solid solution strengthener and will increase the strength of the material linearly with increasing concentration:

$$
\Delta \sigma_{\mathrm{SS}}=K c,
$$

where $c$ is the concentration of the solute, and $K$ is a constant $=17.2 \mathrm{MPa} / \mathrm{wt}$ pct for dilute $\mathrm{Mg}$ in $\mathrm{Al} .{ }^{[25]} \mathrm{In}$ AA 5083 , this results in an estimated $\Delta \sigma_{\mathrm{SS}}=69 \mathrm{MPa}$.

In order for the reinforcement particles to strengthen the material via Orowan bowing, the reinforcement particles must exist within the grain interiors. In the case of Sample 1, which is reinforced with $n-B_{4} C$ particles, previous work has revealed that $\sim 40$ pct of the $n-B_{4} C$ particles exist within the grain interiors. ${ }^{[7]}$ For Sample 2, which is reinforced with $\mathrm{s} \mu-\mathrm{B}_{4} \mathrm{C}$ particles, none of the reinforcement particles may exist within the grain interiors as the particles themselves are larger than the mean metal grain size. However, both samples have cryomilling-induced dispersoids present. The relative volume fraction of these dispersoids can be inferred from the light element content (Table I). For Sample 3, for instance, if all of the $\mathrm{O}, \mathrm{N}$, and $\mathrm{C}$ are assumed to exist as aluminum oxide, aluminum nitride, and aluminum carbide, respectively, the relative volume fractions of each dispersoid are then estimated to be 0.014 , 0.028 , and 0.006 , respectively. In cryomilled $\mathrm{Al}$, the dispersoids are typically $\sim 10 \mathrm{~nm}$ in size and well distributed throughout the metal matrix. ${ }^{[26]}$ These dispersoids and the $n-B_{4} C$ particles will strengthen the material via Orowan bowing and the strength contribution can be estimated as ${ }^{[27]}$

$$
\Delta \sigma_{\mathrm{OR}}=M \frac{0.4 G b}{\pi \sqrt{1-v}} \frac{\ln \left(\frac{\bar{d}}{b}\right)}{\bar{\lambda}},
$$

where $M=3.06$ is the mean orientation factor for Al, $G$ is the shear modulus, $b$ is the magnitude of the burgers vector, $v$ is the Poisson's ratio, $\bar{d}$ is the mean dispersion size taken to be $10 \mathrm{~nm}$ for the dispersoids, ${ }^{[28]}$ and $\bar{\lambda}=\bar{d}\left(\sqrt{\pi / 4 f_{\mathrm{d}}}-1\right)$ is the mean interparticle spacing where $f_{\mathrm{d}}$ is the volume fraction of dispersoids and nanoparticles that may interact with a gliding dislocation. In Sample $1, f_{\mathrm{d}}$ is taken to be the total volume fraction of cryomilling-induced dispersoids (0.048) plus 0.02 , due to the 40 pct of the $5 \mathrm{vol}$ pct of $n-B_{4} C$ particles that are located within the grain interiors (thus $\left.f_{\mathrm{d}}=0.068\right)$, while in Sample $2 f_{\mathrm{d}}$ is taken to be just the total volume fraction of dispersoids $\left(f_{\mathrm{d}}=0.048\right)$. This results in an estimated $\Delta \sigma_{\mathrm{OR}}=171$ and $141 \mathrm{MPa}$ for Samples 1 and 2, respectively.
The strengthening contribution due to the increased dislocation density can be approximated by the Taylor relationship ${ }^{[29]}$ :

$$
\Delta \sigma_{\mathrm{GND}}=\alpha G b \sqrt{\rho_{\mathrm{GND}}},
$$

where $\alpha$ is a constant that is equal to $1.25 .^{[29]} \rho_{\mathrm{GND}}$ is the concentration of geometrically necessary dislocations and increases according to ${ }^{[7]}$

$$
\rho_{\mathrm{GND}}=\rho_{\mathrm{EM}}+\rho_{\mathrm{CTE}}=\frac{8 f_{\mathrm{R}} \varepsilon_{\mathrm{y}}}{b d}+\frac{12 f_{\mathrm{R}}(\Delta \alpha \Delta T)}{\left(1-f_{\mathrm{R}}\right) b d},
$$

where $\rho_{\mathrm{EM}}$ and $\rho_{\mathrm{CTE}}$ are the density of geometrically necessary dislocations due to elastic modulus and coefficient of thermal expansion (CTE) mismatch, respectively, $\varepsilon_{\mathrm{y}}=0.002$ is the yield strain, $b$ is the magnitude of the burgers vector, $d$ is the mean reinforcement particle size, $\Delta \alpha$ is the CTE mismatch, and $\Delta T$ is the magnitude of the largest thermal cycle during thermomechanical processing. As the particle size decreases, the concentration of the interfaces (i.e., dislocation density) increases drastically. $\Delta \sigma_{\mathrm{GND}}$ values are estimated to be 181 and $54 \mathrm{MPa}$ for Samples 1 and 2 , respectively.

If the above four strengthening mechanisms are assumed to superimpose linearly, then the total strength of the composite can be estimated as

$$
\sigma_{\mathrm{c}}=\Delta \sigma_{\mathrm{LT}}+\Delta \sigma_{\mathrm{H}-\mathrm{P}}+\Delta \sigma_{\mathrm{SS}}+\Delta \sigma_{\mathrm{OR}}+\Delta \sigma_{\mathrm{GND}},
$$

resulting in estimated yield strengths of 965 and $728 \mathrm{MPa}$ for Samples 1 and 2, respectively. The estimated yield strength is in excellent agreement for Sample 2 with an error of 2.8 pct from the experimentally measured yield strength of $750 \mathrm{MPa}$. However, Sample 1 is overestimated by $135 \mathrm{MPa}$ or $16.3 \mathrm{pct}$, which is on the same order as the value for $\Delta \sigma_{\mathrm{LT}}$ for Sample 1. This fact indicates the ineffective load bearing of $n-B_{4} \mathrm{C}$ in the matrix. This analysis suggests that as the reinforcement particle size is decreased, there is a transition at which load bearing is no longer operative. This transition may not be a "sharp" transition that occurs at some finite critical particle size, but more likely occurs gradually. Hence, if there is a transition at which $\mathrm{B}_{4} \mathrm{C}$ particles no longer strengthen the composite via load bearing, it also implies that at this transition, $n-B_{4} C$ particles will be ineffective stiffeners.

\section{CONCLUSIONS}

In summary, two different ultrafine-grained $\mathrm{Al}-\mathrm{B}_{4} \mathrm{C}$ MMCs containing either $n-B_{4} C(50 \mathrm{~nm})$ or $s \mu-B_{4} C(500$ $\mathrm{nm})$ reinforcement particles were fabricated under identical processing conditions and with the same nominal reinforcement volume fraction. The MMC containing $\mathrm{n}-\mathrm{B}_{4} \mathrm{C}$ particles, Sample 1, demonstrated $\sim 80 \mathrm{MPa}$ higher strength, but a 4.5 GPa lower stiffness than the $\mathrm{s} \mu-\mathrm{B}_{4} \mathrm{C}$-reinforced composite, Sample 2. The measured values both fall near the lower bound for elastic modulus as predicted by the rule-of-mixtures, but show good agreement with the elastic modulus range 
predicted by the H-S model. However, neither model predicts any difference between the two samples. The lower observed elastic modulus for Sample 1 was accredited to inefficient load transfer from the metal matrix to the reinforcement particles and the influence of microstructure and particle placement relative to that microstructure.

\section{ACKNOWLEDGMENTS}

The authors gratefully acknowledge the Office of Naval Research (ONR) (Grant \# ONR N00014-142-1-0237) under the guidance of Dr. Lawrence Kabacoff as program officer and the Slovak Research and Development Agency (SRDA APVV-0556-12) for providing financial support. The authors also thank the U.S. Army Armament, Research, Development and Engineering Center (Picatinny, NJ) for supplying the $n-\mathrm{B}_{4} \mathrm{C}$ powder.

\section{REFERENCES}

1. R. Casati and M. Vedani: Metals, 2014, vol. 4, pp. 65-83.

2. K.K. Chawla and N. Chawla: Kirk-Othmer Encyclopedia of Chemical Technology, Wiley, New York, 2000.

3. J. Ye, B.Q. Han, Z. Lee, B. Ahn, S.R. Nutt, and J.M. Schoenung: Scripta Mater., 2005, vol. 53, pp. 481-86.

4. Y. Li, Y.H. Zhao, V. Ortalan, W. Liu, Z.H. Zhang, R.G. Vogt, N.D. Browning, E.J. Lavernia, and J.M. Schoenung: Mater. Sci. Eng. A, 2009, vol. 527, pp. 305-16.

5. R. Vogt, Z. Zhang, E. Huskins, B. Ahn, S. Nutt, K.T. Ramesh, E.J. Lavernia, and J.M. Schoenung: Mater. Sci. Eng. A, 2010, vol. 527 , pp. 5990-96.

6. H. Yang, T.D. Topping, K. Wehage, L. Jiang, E.J. Lavernia, and J.M. Schoenung: Mater. Sci. Eng. A, 2014, vol. 616, pp. 35-43.

7. L. Jiang, H. Wen, H. Yang, T. Hu, T. Topping, D. Zhang, E.J. Lavernia, and J.M. Schoenung: Acta Mater., 2015, vol. 89, pp. $327-43$.
8. L. Jiang, K. Ma, H. Yang, M. Li, E.J. Lavernia, and J.M. Schoenung: JOM, 2014, vol. 66, pp. 898-908.

9. Z. Zhang, T. Topping, Y. Li, R. Vogt, Y. Zhou, C. Haines, J. Paras, D. Kapoor, J.M. Schoenung, and E.J. Lavernia: Scripta Mater., 2011, vol. 65, pp. 652-55.

10. M. Balog, P. Krizik, M. Nosko, Z. Hajovska, M.V.C. Riglos, W. Rajner, D.-S. Liu, and F. Simancik: Mater. Sci. Eng. A, 2014, vol. 613, pp. 82-90.

11. M. Balog, T. Hu, P. Krizik, M.V.C. Riglos, B.D. Saller, H. Yang, J.M. Schoenung, and E.J. Lavernia: Mater. Sci. Eng. A, 2015, vol. 648 , pp. 61-71.

12. R.G. Vogt, Z. Zhang, T.D. Topping, E.J. Lavernia, and J.M. Schoenung: J. Mater. Process. Technol., 2009, vol. 209, pp. 5046-53.

13. L. Jiang, H. Yang, J.K. Yee, X. Mo, T. Topping, E.J. Lavernia, and J.M. Schoenung: Acta Mater., 2016, vol. 103, pp. 128-40.

14. M. Bouchacourt and F. Thevenot: J. Common Met., 1981, vol. 82, pp. $227-35$.

15. A.P. Newbery, S.R. Nutt, and E.J. Lavernia: JOM, 2006, vol. 58, pp. 56-61.

16. Z. Hashin and S. Shtrikman: J. Mech. Phys. Solids, 1963, vol. 11, pp. $127-40$

17. D.B. Witkin and E.J. Lavernia: Prog. Mater. Sci., 2006, vol. 51, pp. 1-60.

18. T.D. Topping: Ph.D., University of California, Davis, 2012.

19. J.R. Davis: Properties and Selection: Nonferrous Alloys and Special-Purpose Materials, Asm Intl, 1990.

20. H.S. Kim and M.B. Bush: Nanostruct. Mater., 1999, vol. 11, pp. 361-67.

21. I.A. Ibrahim, F.A. Mohamed, and E.J. Lavernia: J. Mater. Sci., 1991, vol. 26, pp. 1137-56.

22. M.F. Ashby: Materials Selection in Mechanical Design, Butterworth-Heinemann, 2010

23. E.O. Hall: Proc. Phys. Soc. Sect. B, 1951, vol. 64, p. 747.

24. N.J. Petch: J. Iron Steel Inst. Lond., 1953, vol. 173, pp. 25-28.

25. J.R. Davis: Met. Park OH ASM Int., n.d.

26. Y. Li, W. Liu, V. Ortalan, W.F. Li, Z. Zhang, R. Vogt, N.D. Browning, E.J. Lavernia, and J.M. Schoenung: Acta Mater., 2010, vol. 58 , pp. $1732-40$.

27. B.O. Han, F.A. Mohamed, Z. Lee, S.R. Nutt, and E.J. Lavernia: Metall. Mater. Trans. A, 2003, vol. 34A, pp. 603-13.

28. F. Zhou, J. Lee, S. Dallek, and E.J. Lavernia: J. Mater. Res., 2001, vol. 16, pp. 3451-58.

29. F. Tang, I.E. Anderson, T. Gnaupel-Herold, and H. Prask: Mater. Sci. Eng. A, 2004, vol. 383, pp. 362-73. 